\section{Rethinking the root of chronic headaches}

\begin{tabular}{|c|c|c|}
\hline $\begin{array}{l}\text { Chronic headaches are a } \\
\text { leading cause of health burden } \\
\text { worldwide and are debilitating } \\
\text { for people living with the } \\
\text { condition. Pamela Blake, MD, } \\
\text { Director of the Headache } \\
\text { Center of River Oaks, and } \\
\text { Carlton Perry, MD, River Oaks } \\
\text { Plastic Surgery Center, are } \\
\text { exploring the underlying cause } \\
\text { of the condition in the hope } \\
\text { of finding ways to provide } \\
\text { patients with relief from } \\
\text { constant pain. Recently, the } \\
\text { research team has focused } \\
\text { on how nerves in the neck } \\
\text { could be the root of this pain, } \\
\text { challenging the belief that all } \\
\text { headaches have their basis in } \\
\text { the brain or even inside } \\
\text { the skull. }\end{array}$ & 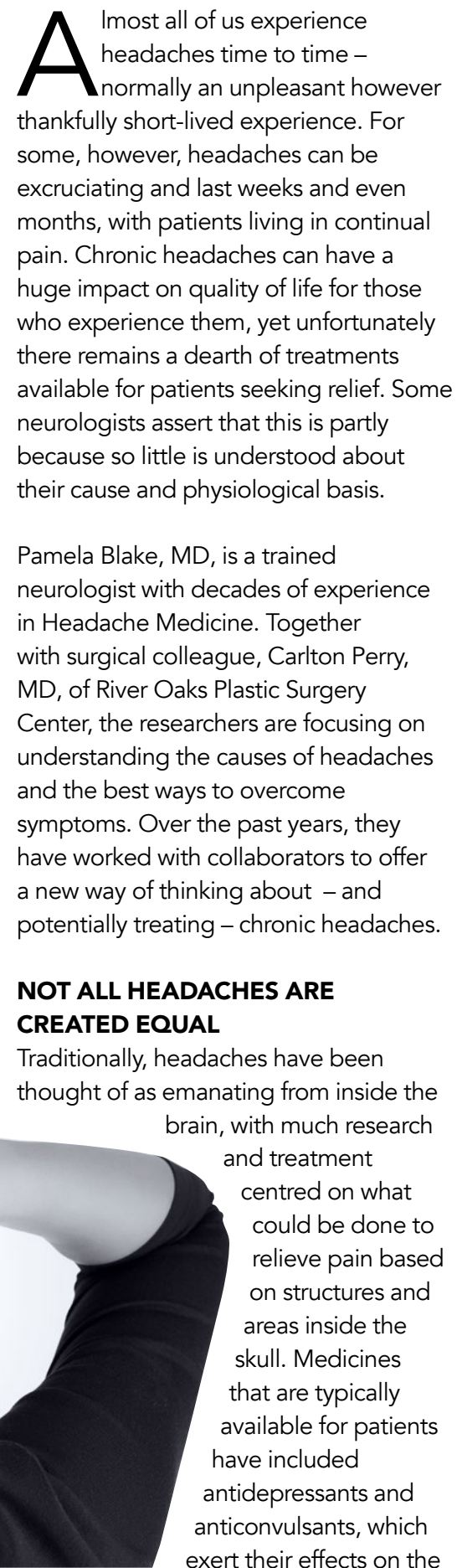 & $\begin{array}{l}\text { One symptom that is often mentioned } \\
\text { is the neck pain that goes alongside } \\
\text { the headache. It is this neck pain that is } \\
\text { commonly experienced by patients that } \\
\text { led Dr Blake to focus her attention on } \\
\text { the neck area and how it could play a } \\
\text { causative role in the headache. } \\
\text { ESTABLISHING THE PHYSIOLOGG } \\
\text { Dr Blake and Dr Perry investigated the } \\
\text { role of the extracranial (outside of the } \\
\text { skull) structures in areas linked to the } \\
\text { pain that Dr Blake's patients described. } \\
\text { They built their understanding of how } \\
\text { extracranial structures might play a } \\
\text { role in head and neck pain based } \\
\text { on foundational work completed by } \\
\text { their colleague, Dr Rami Burstein. Dr } \\
\text { Burstein showed in mouse studies in } \\
\text { 2009 that nerve fibres on the outside } \\
\text { of the skull cross the skulll bones before } \\
\text { connecting to intracranial meninges }\end{array}$ \\
\hline
\end{tabular}

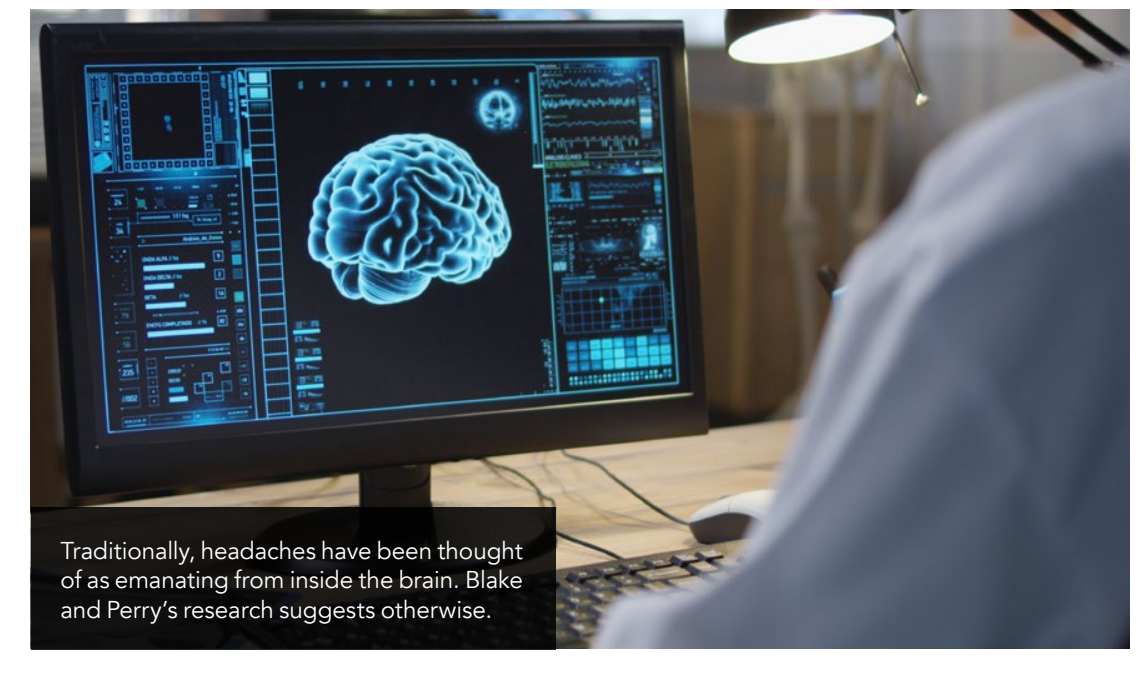

suppressing genes - a pattern that was This was the first firm evident headache. pathology of headaches can be seen outside the skull and is directly linked to extracranial pathology. Moreover, helped elucidate the role of inflammation in people with neck muscle tenderness and chronic headache.

\section{UNREMITTING HEAD} AND NECK PAIN

In a recent review, Dr Blake and Dr Burstein set out the evidence of

pathophysiology of occipital nerve

membranes that cover the brain and spinal cord. This important discovery had established the significance of pain that may be perceived as co from inside the skell, as well as involving features that had been considered to be indicative of intracranial pathology. also suggested a mechanism by which treatments that target the neck and extracranial muscles, such as Botox, may offer relief from headaches.

Previous researchers, particularly Dr Bahman Guyuron, had identified that compression of nerves in the neck and on the outside of the skull could cause pain, and that surgical decompression of the involved nerves could reduce pain. Earlier studies of the condition of nevve compression were of understanding of the pathophysiology the types of headache that patients experienced Drs Blake and Perny were interested to add clarty to the science. In 2016, Dr Blake and Dr Perry showed that there is localised inflammation on the outside of the head in some people living with chronic headaches who also experience neck pain. In ground-breaking research, Dr Perry took biopsies from these patients at the site of the pain in the head, removing a small piece of what is called the calvarial periosteum - a laye of connective tissue covering the skull. Dr Burstein then completed DNA studies of the tissue, comparing the samples from headach suferess to hon-headache control subjects, and showed an uptick in expression for genes linked to patients led the researchers to focus attention on how the neck area could play a causative role in headaches.
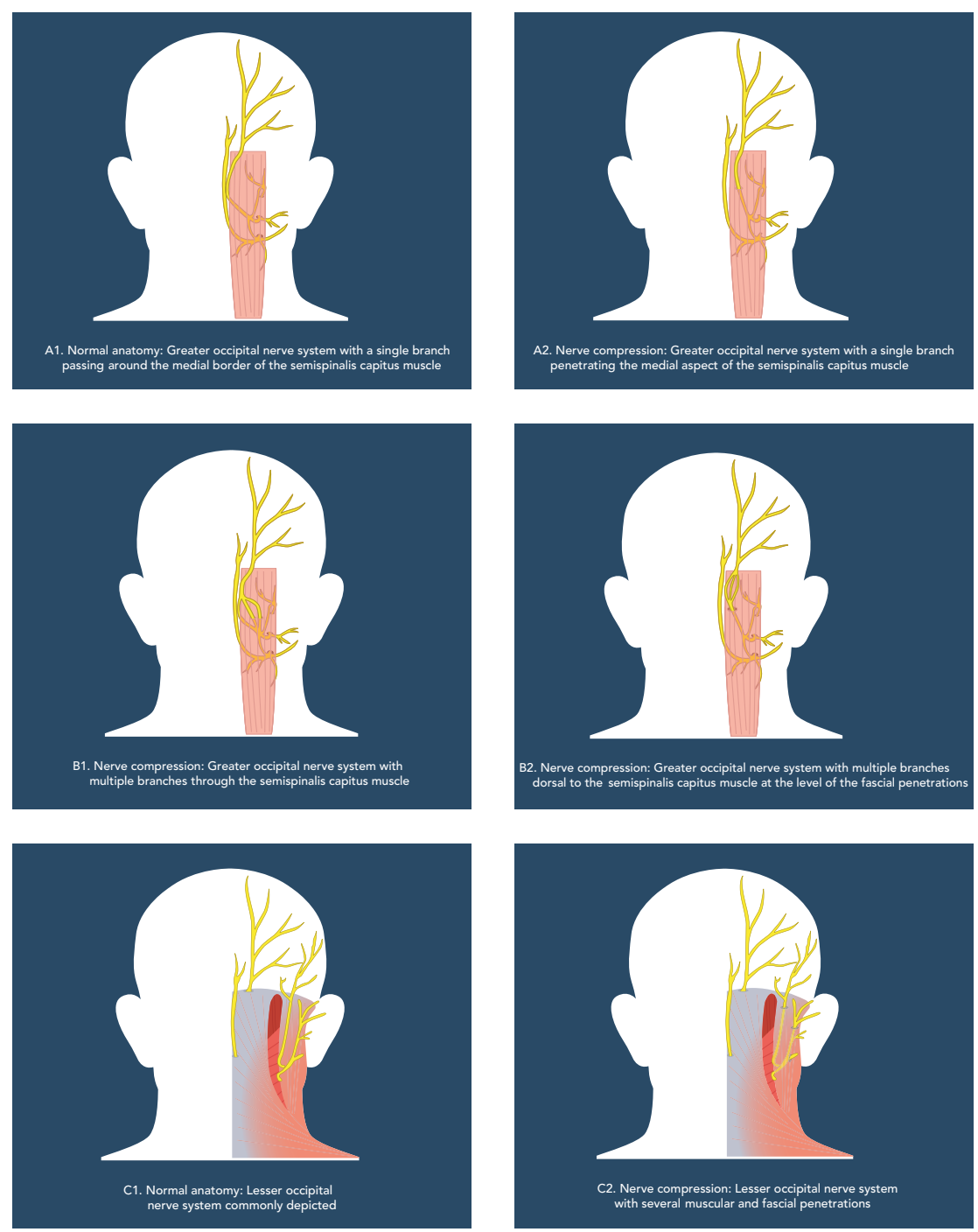

Neck pain frequently mentioned by 

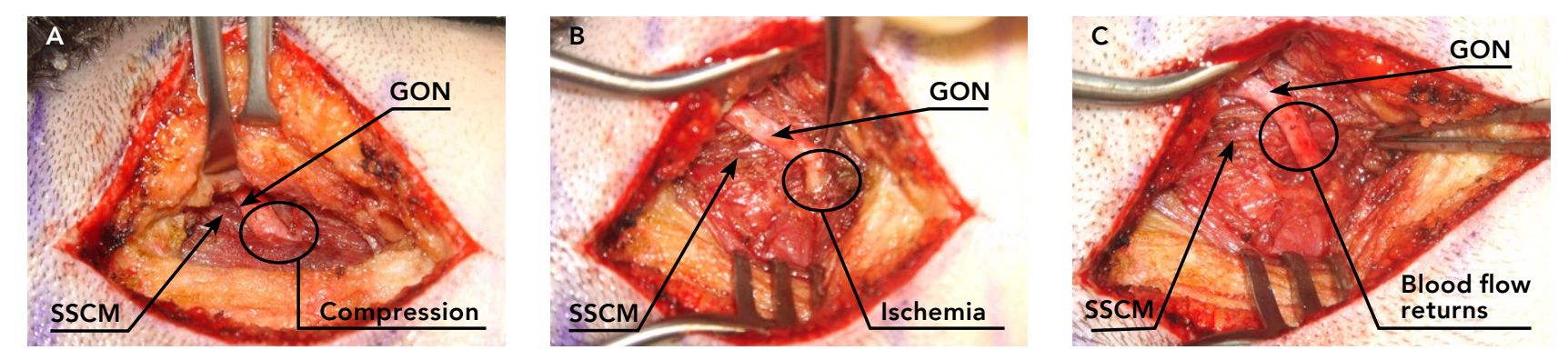

A. The greater occipital nerve (GON) runs through the semispinalis capitus muscle (SSCM) muscle. Compression to the GON causes inflammation and
inflamm inflammatory tissue squeezes GON until blood flow stops (lack of blood flow results in the white appearance of nerve). GON starts to die and causes
pain. B. Loss of blood fllow to the nerve (ischemia). C. Removal of inflammatory tissue relieves pressure on the nerve. Blood flow returns, nerve is no

pain. They believe that these nerves running from the back of the neck to the back of the head, and then, potentially by connections with the nerves that travel through the skull to the meninges could be central to unremitting head an neck pain (UHN). This theory proposes stems from a least in some patients, muscles in the back of the neck and the fascial attachments of those muscles to the skull at the occipital skull at the back of the head. Localised inflammation occurs secondary to the compression, causing pain in the occipital part of the head that can radiate via the connecting

NERVE DECOMPRESSION SURGERY Nerve decompression surgery involves removing compressive inflammatory tissue and muscle from the underlying nerves thought to be involved in the previously, thas attracted debate previously, because it has had mixed careful stulies conducted without types by a qualified neurologist, and also with uneven results when the procedure was performed by inadequately trained surgeons. Additionally, there is a dearth of research around it. Furthermore, research into the effectiveness of surgical procedures is limited due to the absence adequate decompression of all involved nerves. Together, Dr Blake and Dr Perry compare clinical and surgical findings with their eye on after-care and work closely with physical therapists and psychologists quality of life for patients after surgery They believe that nenve decompression surgery could be a game-changer for people living with chronic headaches and that this new way of thinking about headaches could dramatically impact how patients are treated. It has also become clear that identification and treatment of co-occurring conditions, such as anxiety and thus radiate Nerve decompression surgery could be $\begin{aligned} & \text { spasm, are very } \\ & \text { important. Given }\end{aligned}$ a game-changer for people living with that there are so chronic headaches.

the head, causing

more widespread

headaches.

Patients who have UHNP often report symptoms including allodynia - painful non-pain inducing stimuli such as lightly touching the face It also shares some symptoms of migraine, including sensitivity to light. The research team suggest that UNHP should be thought of as a subgroup of chronic headache and of other headache types, including migraine.

atients describe a constant discomfort, feeling of tightness in the back of the neck, and intense bouts of pain that radiate to the front of the head around the temples and forehead. For some, the pain is so constant they become used to $i$, stop noticing the mild neck discomfor and might not report it to their clinician. Many patients struggle to manage their options available. of a control group. However, the case for treatments that look beyond the skull is growing. As headache types very between pattents, it may be that surgey particular type of headache, and such patients must be carefully identifed A recent case study report of seven patients showed that there was significant benefit for four patients, but only limited or no pain relief for three patients. All patients had different headaches types, reiterating the importance of better understanding of individual cases. The challenge therefore is predicting who will best be served by the surgical intervention. Dr Blake and Dr Perry thus suggest that surgery may work in certain cases, and their experience is the tor these individuals, the surgery $m$ ay be life-changing.

In addition to improving the process of identifying candidates for nerve options available,
the findings clearly spotta position of gathering more this potentially life-changing intervention.

\section{LOOKING TO THE FUTURE} Millions worldwide live with chronic associated with headache rises, there is how to tackle the issue. This translationa work has shown that for at least some patients, the neck is the key origin of pain. The evidence Dr Blake and Dr Perry are building provides a clear argument that structures outside of the skull and localised inflammation should be thought of as key to some forms of headache. Whilst nerve decompression surgery research is in its infancy, it could living wh chronic headache. Headache some hope to patients living wish th of debilitating condition. further need to understand more about bring huge relief for a subset of people

\section{Behind the Research}

Pamela Blake, MD

E: pamelablakemd@hcoro.com T: +1 713-426-3337 W: www.headachecenterofriveroaks.com

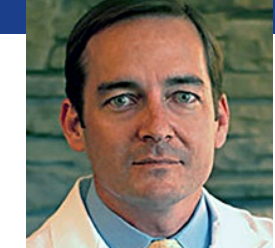

Carlton Perry, MD

Research Objectives

Pamela Blake and Carlton Perry work closely together to further awareness of nerve compression as a cause of chronic head and neck pain

\section{Detail}

Pamela Blake, M.D.

Denter of River Oaks, 2711 Ferndale Street
Houston, TX 77098 USA

Carlton Perry, M.D. Medical Director, River Oaks Plastic Surgery Center, 2707 Fernd
Houston, TX 77098 USA

Bio

Pamela Blake, M.D. completed residency in Neurology at Georgetown
University in Washington, DC, and fellowship in Neuro-Ophthalmology at the Johns Hopkins Hospital
in Baltimore, MD. She is UCNS-

certified in Headache Medicine and is an Adjunct Associate Professor at the McGovern School of Medicine, University of Texas Health Science Center Houston, where she serves as Detation for the neurology reside rotation for the neurology residency.
Blake is the Director of the Headache Center of River Oaks, Houston, Texas.

Carlton Perry, M.D. completed residency in General Surgery at St. Joseph's Medical Center Hospital, training in Plastic Surgery at University of Oklahoma Health Science Center in Oklahoma City, OK. Dr Perry is board certified by the American Board of Surgery and the American Board member of the International Headach Society, American Headache Society, and Southern Headache Society. Dr Rerry is the medical director of the Houston, Texas.

\section{Collaborators}

- Lynne Davis, PhD, and Robert Cuyler,

Pionysia Swett, PA-C and Jill Flury.

- Lynn Nguyen, MA, BS, OTR

\section{References}

Blake, P., et al. (2018). Tracking patients with decompression surgery: A case series. Cephal 033310241880158. doi.10.1177/0333102418801585. Blake, P \& Burstein, R. (2019). Emerging evidence of occipital nerve compression in unremitting head an doi.10.1186/s10194-019-1023-y

- Burstein, R., et al. (2014). EHMTI-0354. Abnormal expression of gene transcripts linked to inflammatory response in the periosteum of chronic migraine patients. implications to extracranial origin of headac do.10.1186/1129-2377-15-S1-K2.

Burstein R et al (2017) Extracranta headache. Current Opinion in Neurology. 30(3):263-271 doi.10.1097WC0.00000000000437. - Perry, C., et al. (2016). Upregulation of inflammatory Implications to extracrasial origin of henic migraineurs: igraine. Annals of Neurology. 79. doi.10.1002/ana.24665.

\section{Personal Response}

What is next for your research?

II Dr Perry and I continue to work together closely to further awareness of nerve compression as a cause of chronic head and neck pain. We suspect that this headache sufferers than originally thought. We have learned that early diagnosis and treatment are key to stopping the progression of pain and the development of hormonal and psychological conditions that can accompany chronic pain. We will also continue to work tissue, which appears to play a critical factor in the
formation of chronic pain.

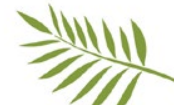

HEADACHE CENTER OF RIVER OAKS 